Portland State University

PDXScholar

Civil and Environmental Engineering Faculty

Publications and Presentations

Civil and Environmental Engineering

2021

\title{
Spatial Accessibility and Equity Analysis of Amazon Parcel Lockers Facilities
}

Jaclyn S. Schaefer

Portland State University, jsschae@pdx.edu

Miguel Figliozzi

Portland State University, figliozzi@pdx.edu

Follow this and additional works at: https://pdxscholar.library.pdx.edu/cengin_fac

Part of the Civil and Environmental Engineering Commons

Let us know how access to this document benefits you.

Citation Details

Schaefer, J. and Figliozzi, M. (2021). "Spatial Accessibility and Equity Analysis of Amazon 24 Parcel Lockers Facilities". Journal of Transport Geography, Forthcoming.

This Pre-Print is brought to you for free and open access. It has been accepted for inclusion in Civil and Environmental Engineering Faculty Publications and Presentations by an authorized administrator of PDXScholar. Please contact us if we can make this document more accessible: pdxscholar@pdx.edu. 


\section{Spatial Accessibility and Equity Analysis of Amazon Parcel Lockers Facilities}

\section{Jaclyn S. Schaefer}

Research Assistant

Department of Civil and Environmental Engineering

Transportation Technology and People Lab

Portland State University, Portland, Oregon, 97201

\section{Miguel A. Figliozzi (corresponding author)}

Professor

Department of Civil and Environmental Engineering

Transportation Technology and People Lab

Portland State University, Portland, Oregon, 97201

Email: figliozzi@pdx.edu

\section{Please cite as}

Schaefer, J. and Figliozzi, M. (2021). "Spatial Accessibility and Equity Analysis of Amazon Parcel Lockers Facilities". Journal of Transport Geography, Forthcoming. 


\section{Spatial Accessibility and Equity Analysis of Amazon Parcel Lockers Facilities}

Abstract

31 The onset of the COVID-19 pandemic has accelerated the growth of e-commerce and home

32 deliveries. Automated parcel lockers are a way to improve delivery efficiency, but despite their

33 rapid growth, little is known about their accessibility and equity impacts. Among e-commerce

34 players in the U.S., Amazon stands out by its large market share. This research studies the

35 location of Amazon lockers in Portland, Oregon utilizing highway, land use, employment, and

36 sociodemographic datasets. Geographical tools and cluster analysis are utilized to estimate

37 accessibility and equity metrics. Lockers tend to be located in mixed-use areas and can be

38 utilized by a large percentage of the population. However, the equity metrics indicate that the

39 current distribution of lockers could be improved to reach traditionally underserved populations.

40 Given the environmental and economic advantages of lockers, policymakers should encourage

41 the expansion of this type of last mile solution to avoid market failures in areas that are currently

42 underserved.

Keywords: E-commerce, parcel lockers, last mile and urban logistics, accessibility, equity, 45 market failure 


\section{INTRODUCTION AND MOTIVATION}

48 The last mile is often said to be the most expensive and least efficient segment of the supply

49 chain. The high costs of the last mile are in part driven by a lack of economies of scale due to increasingly fragmented orders. One strategy suggested for mitigating the high costs and inefficiencies in the last mile of business to consumer (B2C) deliveries is the implementation of parcel lockers that operate as unmanned pick-up or collection points, where a consumer uses a variable electronic code to open the locker and retrieve a shipment. Lockers are typically offered in various sizes, and some may also serve as drop-off points for consumer returns or to send parcels from locker to locker as well as from locker to home (or vice versa). Cost reductions gained by using lockers are significant. For example, in Poland - a country leader in the adoption of lockers - the cost of sending a parcel from locker to locker is $15 \%$ to $30 \%$ less than sending from locker to home, depending on the package size (INPOST, 2021).

Lockers have been successfully used by Amazon, the largest e-commerce company in the U.S. Amazon has a complex logistics network with a recent push towards vertical integration of ecommerce activities that includes lockers where customers can pick up parcels (Rodrigue, 2020). Amazon started implementing locker stations in 2011 and as of 2018, was the majority provider of public access lockers, located in over 900 cities in the U.S. (Holsenbeck, 2018). Its share of the U.S. e-retail market also takes a staggering lead against its competitors (Lunden, 2018). Due to Amazon's great influence on U.S. e-commerce and its rapidly expanding logistics services, the current study focuses only on Amazon lockers.

Data from the U.S. indicate that during the COVID-19 pandemic, home deliveries disproportionally benefit higher-income, more educated sectors of the population (Figliozzi \&

71 Unnikrishnan, 2021). But, even before COVID, results from the 2017 NHTS (National

72 Household Travel Survey) indicate that in the U.S., households above the poverty line are twice

73 as likely to make online purchases than households below the poverty line (FHWA, 2018). In

74 this context, and since parcel lockers reduce delivery costs, it is relevant to study the distribution 75 of lockers in relation to equity metrics. 
This research studies the distribution of 176 Amazon locker locations in the Portland, OR

78 metropolitan area to answer two research questions: (a) How are lockers distributed with respect to accessibility measures such as population coverage and employment by mode of transportation? and (b) What are the equity implications of the current distribution of lockers? To answer these questions, several datasets are analyzed utilizing geographic tools and cluster analysis. The lockers studied in this research are a closed system (i.e. only used by Amazon) but with public access. Other types of locker types can be utilized to improve transportation,

84 accessibility and equity goals as discussed in Section 7.

Although parcel lockers are widely used in countries like Poland (Iwan et al., 2016), they are still a relatively recent phenomenon in the U.S. and to the best of the authors' knowledge no previous research effort has attempted to analyze accessibility metrics for parcel locker locations in whole urban areas of the U.S or by utilizing cluster analysis. In addition, the focus on equity and market failure utilizing multiple variable groups (income, internet access, transportation, built environment, socio-demographic, and land use variables) is novel and has not been found in the

92 literature review.

The research is organized as follows: Section 2 reviews relevant literature. Section 3 details the data and Section 4 describes methods employed in this analysis. Section 5 presents the results of the accessibility analysis. Section 6 provides the equity analysis results. Section 7 discusses the results, mainly focusing on the potential role of government to avoid market failures in terms of parcel locker accessibility and equity. Finally, Section 8 summarizes main findings and conclusions.

\section{LITERATURE REVIEW}

101 The literature related to parcel lockers has been growing more rapidly in the last few years and 102 clearly indicates that parcel lockers have many advantages (Viu-Roig \& Alvarez-Palau, 2020).

103 The usage of parcel lockers in lieu of home deliveries allows delivery consolidation while 104 decreasing vehicle miles traveled (Deutsch \& Golany, 2018; Iwan et al., 2016; Verlinde et al., 105 2019). Parcel lockers can also benefit the supply chain by consolidating the pick-up of returned purchases. More than half of all online shoppers in most countries served by logistics company 
107 UPS have returned an online purchase (Morganti, Seidel, et al., 2014), adding additional burdens 108 and costs to supply chains. Parcel deliveries contribute to loading zone shortages in urban areas 109 and increasing carbon emissions (Chen et al., 2017; Edwards et al., 2009; Moroz \& Polkowski,

110 2016; SCTLC, 2018), and delivery consolidation utilizing lockers may help alleviate these

111 issues. Data from focus groups indicate that the self-service aspect of lockers not only reduces

112 costs but may also increase value for the customers (Vakulenko et al., 2018). In addition, the use

113 of parcel lockers may help fulfill safety recommendations regarding the COVID-19 pandemic as

114 they are befitting of social distancing measures and contactless delivery.

116 Regarding location preferences, consumers in Sweden indicated a preference for lockers near

117 shopping areas and home. Proximity to subway or bus stops was also identified as a preference

118 (Vikingson \& Bengtsson, 2015). In Poland, consumers strongly preferred locations near their

119 home or on the way to work, while the least attractive locations were near shopping centers and

120 transit stops (Iwan et al., 2016; Lemke et al., 2016). In Brazil, the top three preferred locations

121 were supermarkets, stores, and shopping malls (Oliveira et al., 2017). In Korea, Lee et al. (2019)

122 believe placing parcel lockers along the daily life path of consumers and near public

123 transportation will enhance their utilization. In France, Morganti et al. (2014) found that the

124 average distance to the nearest pick-up point was only $1.6 \mathrm{~km}(1 \mathrm{mi}$.) in urban areas and $6 \mathrm{~km}$

125 (3.7 mi.) in rural areas and over 50\% of the pick-up points were located within $400 \mathrm{~m}(0.25 \mathrm{mi})$

126 of a commuter railway station. Comparing urban, suburban, and rural regions, pick-up points

127 were over-represented in the urban areas with respect to their share of the population. In South

128 East Queensland (Australia), the presence of a parcel locker was associated with proximity to

129 highways and public transport, high population density, a good balance of population and jobs,

130 and areas with higher rates of household internet access (Lachapelle et al., 2018). Here, lower

131 income populations might have a slight advantage when it comes to parcel locker presence.

132 However, lower automobile ownership rates and a limited ability to travel longer distances,

133 which are associated with lower incomes, counterbalance that benefit (Lachapelle et al., 2018).

134 Finally, Fang et al. (2019) analyzed the distribution of Amazon Lockers in Los Angeles County

135 and detected a positive spatial correlation of locker counts per U.S. Census tract using the Global

136 Moran I Index. Higher education levels, internet access, and walking mode share had the highest 
137 correlations with the variable locker counts. The regression analysis produced counterintuitive

138 signs for variables such as population and internet access likely due to multicollinearity.

140 A recent overview of the locker location literature comes up with six factors that affect locker

141 location: potential 24/7 service availability, accessibility by different modes, security,

142 environmental impacts, installation costs, and regulatory constraints (Lagorio \& Pinto, 2020).

143 The e-commerce literature indicates that household income and internet usage are key variables

144 that affect online purchases; higher-income households with more access to computers and the 145 internet are more likely to make purchases online (Cao et al., 2012; Crocco et al., 2013; De

146 Blasio, 2008; Farag et al., 2007). However, underserved populations appear to be less likely to

147 participate in online shopping activities. During the COVID-19 lockdown period, significantly

148 higher rates of home deliveries were associated with higher income and education levels, more

149 access to electronic devices and internet, automobile ownership and usage, larger households,

150 and white households (Figliozzi \& Unnikrishnan, 2021). For consumers reliant on transit, the

151 installation of common carrier lockers at transit stations has been proposed to improve access

152 (Keeling et al., 2021).

153

154 Although previous studies have identified parcel locker location preferences, there has not been

155 extensive research assessing existing locations of lockers in whole metropolitan urban areas of

156 the U.S. focusing on equity metrics and utilizing clustering methods with income, internet

157 access, transportation, built environment, socio-demographic, and land use variables. While

158 cluster analysis has been utilized in transportation studies to analyze freight, transit, crashes,

159 environmental justice, and mobility (Cidell, 2010; Diaz-Varela et al., 2011; du Preez et al., 2019;

160 Haustein \& Nielsen, 2016; Schweitzer, 2006) it has not yet been applied to study locker

161 distributions and/or equity.

\section{DATA COLLECTION}

163 The study area is defined as the Oregon portion of the Portland-Vancouver-Hillsboro

164 metropolitan statistical area. This research does not focus on lockers that can be installed inside

165 buildings or complexes for the exclusive benefit of its residents or employees. It focuses on

166 lockers that are mostly installed on sidewalks and public access areas. The dataset of lockers 
167 includes the name, coordinates, and host site (where available) of each locker facility. A total of 168176 Amazon locker facilities were identified in the study area in October 2020 and Figure 1

169 shows housing density at U.S. Census block level overlaid by the locker locations.

In total, 62 variables related to age, income, housing, means of transportation to work, race and origin, educational attainment, employment, and computer and internet service accessibility were 173 collected from the U.S. Census Bureau American Community Survey (ACS). These 62 variables

174 are listed in Table A. 1 in the appendix. The socio-demographic data are aggregated at the block 175 group level - the smallest level of geographic detail with a wide range of publicly available 176 variables. Census block groups are usually comprised of contiguous clusters of census blocks, 177 containing between 600 and 3000 people (U.S. Census Bureau, 2019), and their boundaries can 178 be viewed in Figure 1.

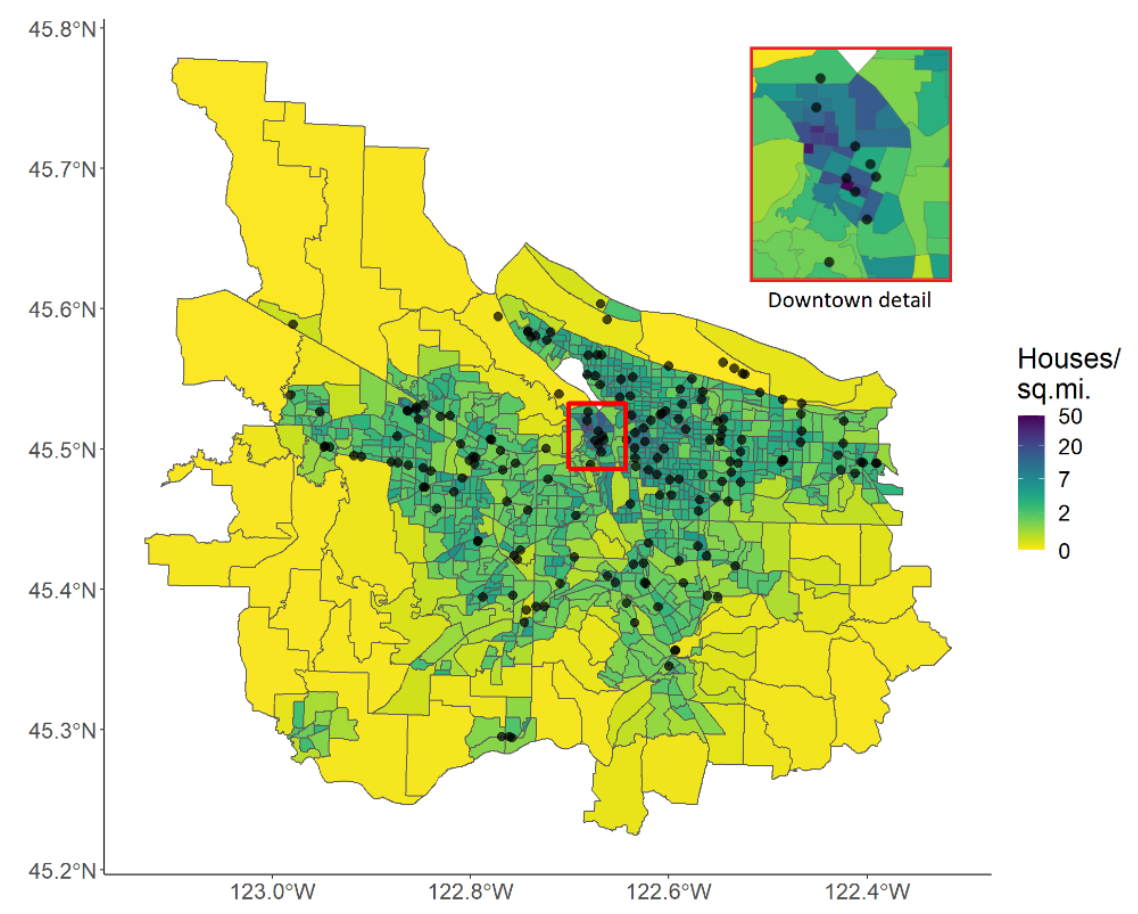

Figure 1: Study area and housing density with Amazon locker locations.

A GIS shapefile of the street network in the area provided by the local MPO was used to investigate locker locations in relation to transportation facilities. Another GIS shapefile

184 containing Oregon zoning data was obtained from the Oregon Spatial Data Library to assess land 185 use patterns associated with Amazon locker locations. Data on the business and employment patterns of the study area were downloaded from the U.S. Census Bureau's ZIP Code Business Patterns (ZBP) dataset for 2018. This data contains information about the number and type of 
188 business establishments, the number of employees, and payroll figures, aggregated at the ZIP

189 Code level. The establishment types are categorized according to the North American Industry

190 Classification System (NAICS).

\section{METHODS}

192 The dataset containing information about the Amazon lockers was obtained using the Google

193 Places API adapting a Python code from Fang et al. (2019). After locating the lockers, a kernel

194 density estimation (KDE) was applied to each observation (point) to distribute its spatial

195 influence based on a given bandwidth; i.e., a locker located at the border of two Census blocks

196 services the population in both areas, but beyond a certain bandwidth, the influence tapers to

197 almost null. The density of Amazon lockers across the study area was calculated using KDE with

198 the function density.ppp from the package spatstat in R (Baddeley et al., 2015). A gaussian

199 kernel function was chosen for the KDE, the standard form of which is shown in Equation 1

200 where $d$ represents the distance from the locker. The kernel $(K)$ is scaled as in Equation 2 where

$201 h$ represents the bandwidth and $e$ is Euler's number or constant.

202

$$
\begin{aligned}
& K(d)=\frac{1}{\sqrt{2 \pi}} e^{-\frac{1}{2} d^{2}} \\
& K_{h}(d)=\frac{1}{h} K\left(\frac{d}{h}\right)
\end{aligned}
$$

Equation 1

Equation 2

203

204 For this analysis, the bandwidth was chosen to represent the maximum distance a consumer

205 would be likely to walk to retrieve a parcel. Oliveira et al. (2019) used a $1000 \mathrm{~m}$ (0.6 mi.) radius

206 (bandwidth) when calculating the kernel density of potential collection and delivery points in

207 Brazil. In New Zealand the median tolerable walking distance to a collection point was $1.46 \mathrm{~km}$

208 (0.9 mi) (Kedia et al., 2019). In Seattle, light rail passengers most frequently chose up to a six

209 block distance (approximately $1 / 4$ to $1 / 2$ mile given the average size block) when asked how far

210 they would be willing to walk with a parcel (SCTLC, 2018). Other studies noted a consumer

211 preference for minimizing the required travel distance to lockers for parcel retrieval (Iwan et al.,

212 2016; Lemke et al., 2016; Vikingson \& Bengtsson, 2015). A conservative bandwidth of a half

213 mile was selected for the current KDE. 
215 A small percentage of missing data was encountered across four of the 62 ACS variables used.

216 The percentage of missing values within these four variables ranged from $1.1 \%$ to $9.5 \%$ over all

217952 block groups within the study area. Rather than exclude observations (i.e. block groups) with

218 missing values from the analysis, the missing values were imputed using the imputePCA function

219 in the R package, miss MDA (Husson \& Josse, 2020).

220

The literature review indicates that income and access to computers and internet service are key

222 variables affecting online purchases. Mode share and built environment variables are of interest

223 from a transportation policy point of view. Also, variables such as education, race, age, home

224 ownership, household size, and employment status are key variables from an equity perspective.

225 Hence, four groups of ACS variables were created to represent different aspects of locker access

226 equity: (1) income, (2) computer and internet access, (3) prevalent built environment and

227 transportation mode, and (4) other non-income demographic factors such as age, race or origin,

228 household occupancy, educational attainment, and work status. Income was placed in a separate

229 group because it is key factor affecting both online purchases and equity. All variables used in

230 the analysis and their basic descriptive statistics are provided in Table A. 1 of the appendix. For

231 each of the four ACS variable groups, a cluster analysis was performed.

233 Clustering classifies observations into groups (clusters) by computing a measure or distance of

234 the similarity between each pair of observations. Traditional clustering methods like k-means

235 aim to minimize total intra-cluster variation (also known as total within-cluster variation).

236 Traditionally, the within-cluster variation $(W)$ is defined as the sum of squared Euclidean

237 distances between items and a centroid:

238

$$
W\left(C_{k}\right)=\sum_{x_{i} \in C_{k}}\left(x_{i}-\mu_{k}\right)^{2}
$$

239 where:

$240 x_{i}$ is a data point belonging to the cluster $C_{k}$

$241 \mu_{k}$ is the mean value of the points assigned to the cluster. 
243 Each observation $\left(x_{i}\right)$ is assigned to a given cluster such that the sum of squares (SS) distance of

244 the observation to their assigned cluster centers $\left(\mu_{k}\right)$ is minimized. The total within-cluster

245 variation is defined as follows:

246

$$
T W C=\sum_{k=1}^{k} W\left(C_{k}\right)=\sum_{k=1}^{k} \sum_{x_{i} \in C_{k}}\left(x_{i}-\mu_{k}\right)^{2}
$$

Equation 4

247

248

249

250

251

252

253

254

255

256

257

258

259

260

The total within-cluster sum of square measures the compactness (i.e., goodness) of the clustering and the goal is to make it as small as possible while keeping a reasonably low number of clusters that are easy to interpret or visualize.

The cluster analysis for each equity category was an iterative, multi-step process. The first step was to perform a hierarchical cluster analysis using Ward's method (R function hclust with method = "ward.D2"). This hierarchical cluster analysis produced an object describing the resulting dendrogram, which was then cut into k clusters. The centroids of these clusters were used to define the initial points for a k-means cluster analysis ( $\mathrm{R}$ function kmeans). The process was iterated for multiple values of $\mathrm{k}$ ranging from two to six. Solutions with random centroids were also obtained to see if there was a TWC improvement. Interpretability of the results, mapping of the clusters and their spatial contiguity, plots of the total within sum of squares (TWC), and the percent deviations of the cluster averages from the median cluster averages were utilized to select an appropriate value for $\mathrm{k}$.

The results of the iterative clustering process indicated the block groups would be best divided into three clusters for the income, computer and internet access, and transportation equity categories. The non-income demographic category was best represented by four clusters. For each equity category, the KDE was integrated over the cluster areas to obtain a total expected locker count per cluster. Next, the share of each cluster's population within various distances of a locker was estimated by constructing radial buffers around the lockers as a function of transporation mode. For pedestrians, conservative buffers of 0.25 miles and 0.5 miles were selected based on the range of walking distances cited in the reviewed literature. To estimate a range of reasonable biking buffers studies by Blanc \& Figliozzi and Kedia et al. $(2016$; 2019) 
272 were utilized. Median actual biking distances in the Portland area for shopping, errands, or 273 personal business were stated as 1.3 miles to 3.1 miles. Thus, biking buffers of 1.5 miles and 3

274 miles were determined as reasonable. Finally, driving buffers of 3 miles and 5 miles were

275 selected based on the average car trip length of 4.4 miles in the Portland region (Small, 2016).

276 When analyzing buffers it is important to consider that proximity is key, especially for users that

277 walk or cycle to the locker. It should also be considered that in many cases, users pick up a

278 package at the end of a trip chain, for example when returning home after work or after running 279 errands.

\section{ACCESSIBILITY ANALYSIS}

281 This section discusses locker accessibility in terms of business location characteristics, land use, 282 and proximity to transportation facilities, home, and work.

\section{5.1 CHARACTERISTICS OF BUSINESS LOCATIONS}

284 The majority of lockers (122 of 176 lockers, or 69.3\%) are located inside or on the property of a 285 convenience store. The next most common hosts for an Amazon locker are drugstores (22 286 lockers, or 12.5\%), department stores (9 lockers, or 5.1\%) and grocery stores (8 lockers, or 287 4.5\%). The remainder of the hosts included gyms, banks, restaurants, storage facilities, a hotel, a 288 retirement community, a go-kart center, and other retailers. This distribution is compatible with 289 the literature, which indicated one of the best sites for parcel lockers is next to convenience 290 stores (Iwan et al., 2016). The distribution of locker hosts observed in the Portland area also 291 seems reasonable when considering a few of Amazon's business partnerships. For instance, early 292 in the locker implementation, convenience store brand 7-Eleven partnered with Amazon to host 293 locker facilities. Amazon has partnered with the drug store, Rite Aid, more recently (Cosgrove, 294 2019). Amazon suggests that hosting a locker can increase foot traffic and drive sales of small 295 dollar-amount purchases (Amazon, 2019). Amazon also has business partnerships with Chase 296 Bank and Sprint, which helps to explain the few, somewhat unlikely locker hosts of a 297 communications store and two banks. Additionally, Amazon owns grocer Whole Foods and 298 installing lockers in those grocery stores may provide benefits for both businesses. 


\subsection{TRANSPORTATION AND LAND USE}

300 The nearest roadway to each locker facility was identified and the distance to it was calculated to 301 explore locker access from different types of road facilities. In addition, the distances from each

302 locker facility to the nearest roadway of each classification (collector, arterial, highway, and 303 freeway ramp) were calculated. While the average and median distances from lockers to freeway 304 ramps or highways were close to one mile or more, the average and median distances from 305 lockers to arterials and collectors were much smaller, ranging from a couple hundred feet to less 306 than a quarter mile. It follows that most Amazon lockers were located closest to an arterial road 307 (101 lockers, or 57.4\%), followed by a collector road (52 lockers, or 29.5\%), a highway (15 308 lockers, or $8.5 \%$ ), and a freeway ramp (8 lockers, or $4.5 \%$ ). Arterial roads typically provide high 309 visibility to businesses and serve higher volumes of motorized traffic compared to lower classed 310 roads. Recalling that the majority of locker hosts were convenience stores which tend to thrive in

311 high traffic areas, it is logical that most of the lockers were located closest to arterial roads.

312 Transit routes are also more likely to follow arterial roads, but access by bicycle or walking may 313 be reduced if low traffic stress bicycle and pedestrian facilities are not provided.

315 The zoning shapefile was overlaid by the Amazon locker locations and the land use category 316 corresponding to each location was extracted in R. The locker facilities were predominantly 317 located in mixed-use commercial and residential zones (120 lockers, $68.2 \%$ ), with commercial 318 zones being the next most common (44 lockers, $25 \%$ ), followed by industrial ( 8 lockers, $4.5 \%$ ).

319 The zoning types corresponding to areas of very low population density such as forest, farm, 320 rural, natural areas, or parks did not contain any locker facilities.

\subsection{PROXIMITY TO HOME AND WORK}

323 One of the most often cited preferences of consumers for locker locations was near their home.

324 Buffer ranges around the lockers were created for the walking, biking, and driving distances. A

325 range of the number of households within the buffers was then estimated using areal

326 proportioning for the entire study area as a metric to gauge the average locker proximity to

327 residences. These results are displayed in Table 1 along with the range of percentages of total

328 houses in the study area within the locker buffers. These calculations estimate that almost $85 \%$ of 
329 households in the study area are within 1.5 miles of an Amazon locker and 97\% of households 330 are within five miles.

331 Table 1: Range of estimated number of households within reach of Amazon lockers by mode.

\begin{tabular}{l|r|r|r|r}
\hline \multirow{2}{*}{ Mode (Dist. Range) } & \multicolumn{2}{|c|}{ Households } & \multicolumn{2}{c}{ Employment } \\
\cline { 2 - 5 } & HH (Thous.) & \% of Total HH & Emp. (Thous.) & \% of Total Emp. \\
\hline Walk (0.25-0.5 Mi.) & $81-232$ & $12.6-36.1$ & $103-285$ & $11.7-32.4$ \\
\hline Bike (1.5-3.0 Mi.) & $546-605$ & $84.9-94.0$ & $673-785$ & $76.4-89.1$ \\
\hline Drive (3.0-5.0 Mi.) & $605-624$ & $94.0-97.0$ & $785-828$ & $89.1-93.9$ \\
\hline
\end{tabular}

334 The map in Figure 2 displays the locations of the lockers with a 0.5 -mile buffer, shaded

335 according to the estimated number of households (in thousands) within the buffer. The map

336 shows that lockers with the greatest number of households within the buffer distance tend to be

337 located in the city center and in the close-in neighborhoods. This observation was consistent

338 across all buffer distances.

340 Another frequently cited preference was for locker locations near the consumer's workplace.

341 Table 1 gives the estimated ranges for the number of employees and the percentage of the study

342 area's total employment within the range of buffer distances established for walking, biking, and

343 driving. Approximately three-quarters of employees are within 1.5 miles of an Amazon locker.

344 The lockers with a 0.5 -mile buffer are again shown in Figure 3 but shaded according to the

345 estimated employment within the buffer area. Note that in this figure, the scale is logarithmic.

346 The employment density is much higher in the central city region, thus, the lockers with the

347 greatest number of employees within 0.5 miles also tend to be located in that area. 
349

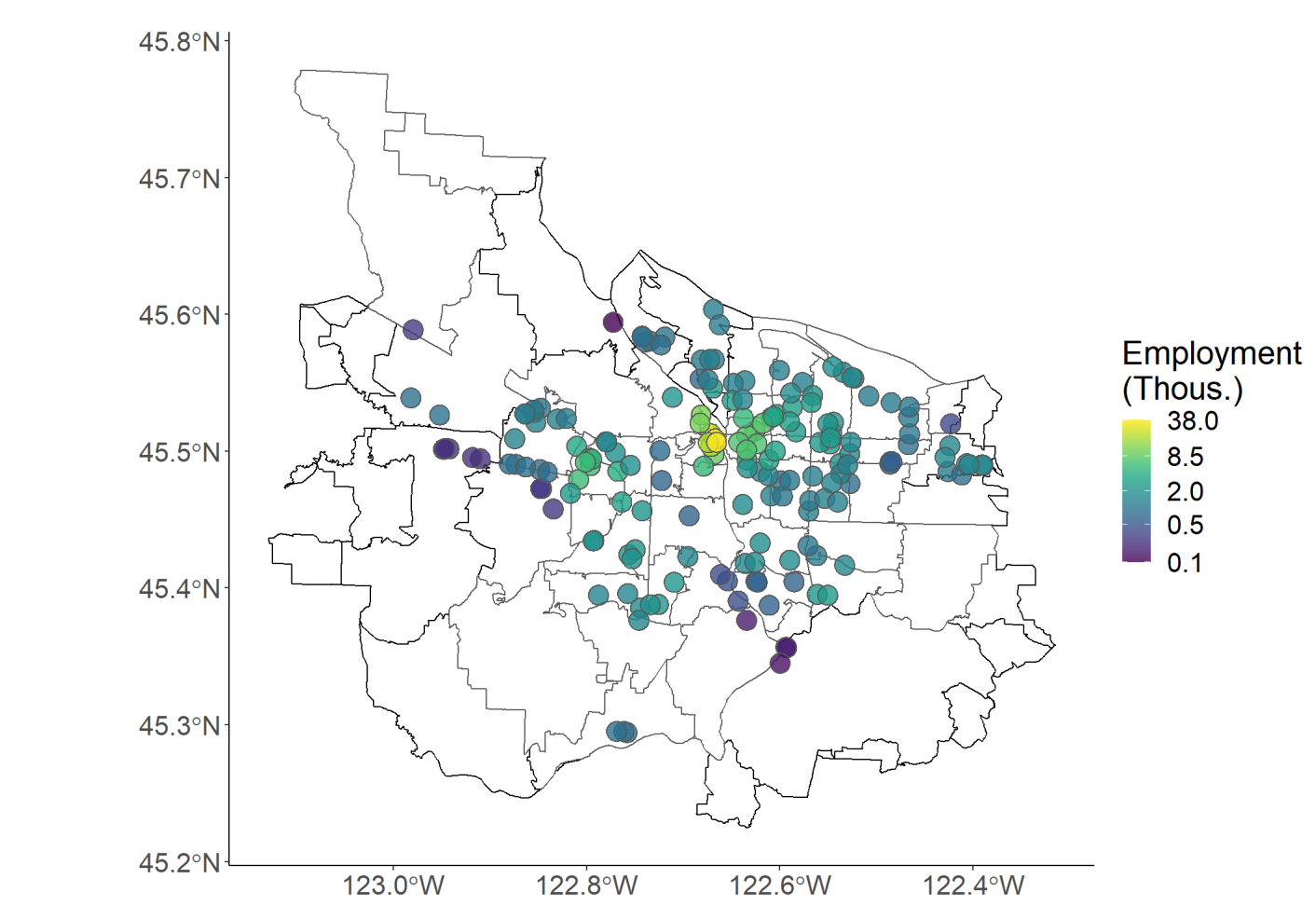

Figure 2: Estimated number of households within a 1/2 mile of an Amazon locker.

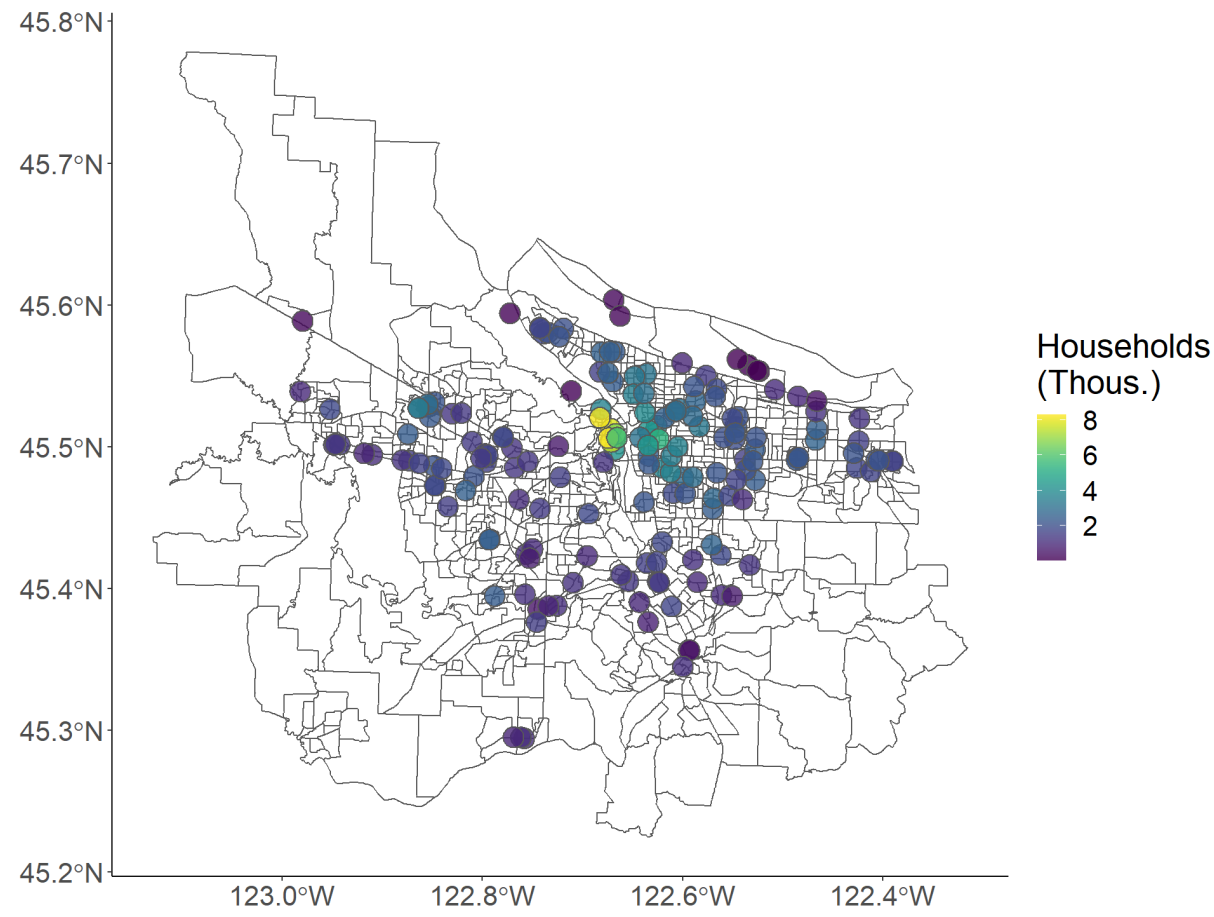

Figure 3: Estimated employment within a 1/2 mile of an Amazon locker. 
356 Evaluating equity is complex and can take many forms depending on the categorization of

357 populations, the performance measures evaluated, and what impacts are considered. Establishing

358 parcel locker facilities in traditionally underserved communities (such as non-white, low-income,

359 transportation disadvataged, etc.) is important to achieve equitable access to basic services such

360 as mail and package distribution. This section discusses the results from the cluster analyses with

361 respect to the distribution of Amazon lockers.

\section{6.1 INCOME}

363 A map depicting the results of the cluster analysis for the income category can be seen in Figure

364 4. It appears that block groups in Cluster 3 are more prominent in the eastern portion of the study 365 area and block groups in Cluster 1 are generally found in the central region, relative to east-west.

366 Block groups in Cluster 2 appear to comprise the largest portion of land area in the study region.

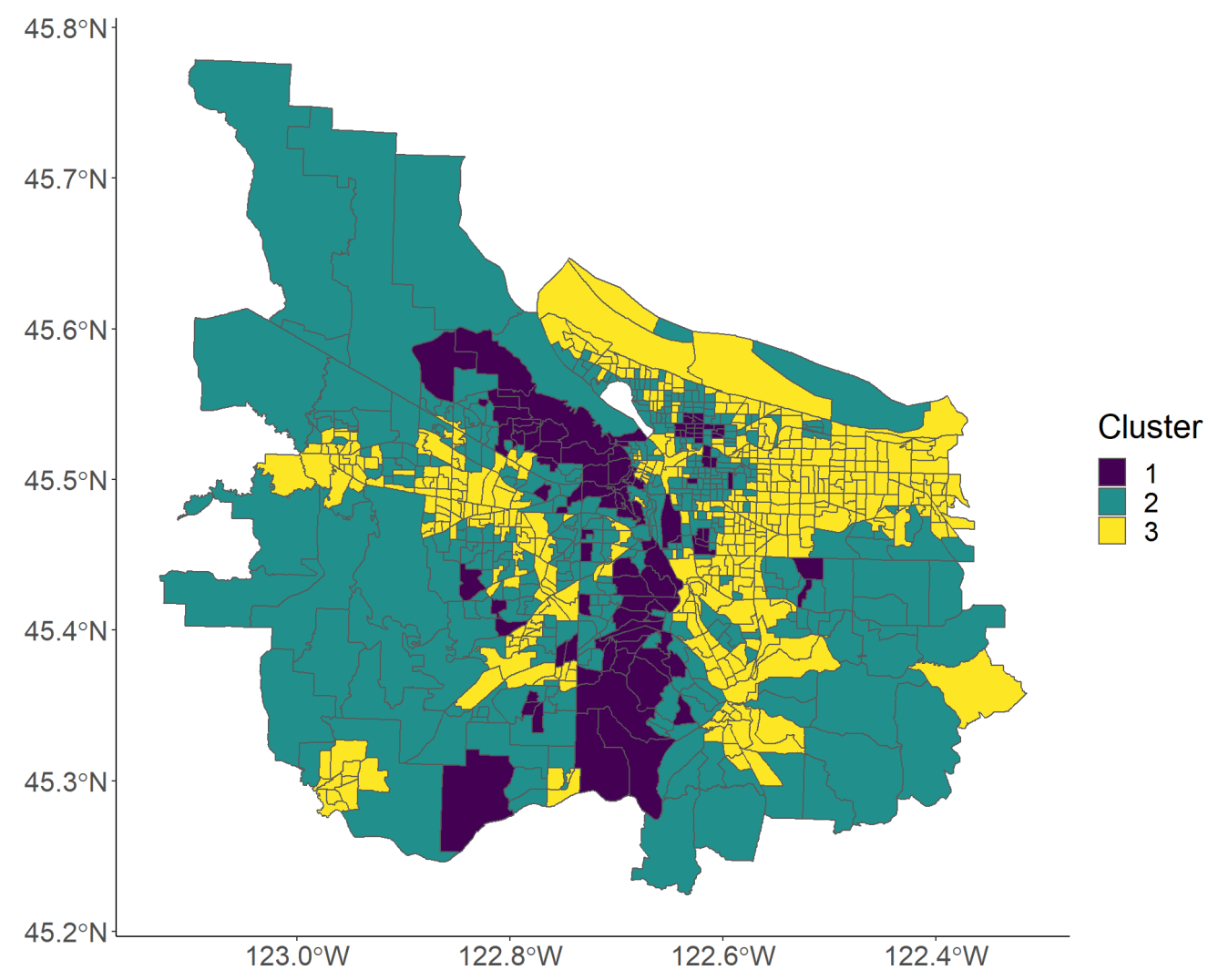

Figure 4: Income cluster results. 
371 Table 2 provides a quantitative description of the characteristics of each income cluster. The key

372 variables showing the most variance among clusters are displayed. Higher income population

373 and households (relative to the median cluster) tend to comprise Cluster 1, and lower-income

374 population and households tend to be located in Cluster 3. The differences between groups are

375 substantial. The average densities of Amazon lockers per square mile (based on the integrated

$376 \mathrm{KDE}$ ), per thousand population, and per thousand households, and the average household

377 incomes for the Income clusters are also provided in Table 2. The density of lockers per square

378 mile within Cluster 3 is three to four times greater than in Cluster 1 or Cluster 2 (0.51 versus

3790.15 and 0.12 , respectively). The average expected density per thousand population and per

380 thousand households is also greatest in Cluster 3, though the differences from the other two

381 clusters are less pronounced. The range of population in thousands per cluster within the

382 walking, biking, and driving locker buffer ranges is also shown in Table 2. The percentage of the

383 total cluster population within the buffers is also given. These results further suggest that Cluster

3843 has greater access to the Amazon lockers overall, and particularly by pedestrian or bicycle

385 modes.

386 Table 2: Income cluster characteristics

\begin{tabular}{|c|c|c|c|}
\hline Key Variables & $\begin{array}{l}\text { Cluster } 1 \\
\text { "High" }\end{array}$ & $\begin{array}{l}\text { Cluster } 2 \\
\text { "Medium" }\end{array}$ & $\begin{array}{c}\text { Cluster } 3 \\
\text { "Low" }\end{array}$ \\
\hline Median Housing Unit Value* & $\$ 674,054$ & $\$ 434,858$ & $\$ 286,790$ \\
\hline Average $\mathrm{HH}$ Income & $\$ 186,975$ & $\$ 109,166$ & $\$ 65,941$ \\
\hline Median HH Income & $\$ 145,813$ & $\$ 89,369$ & $\$ 54,805$ \\
\hline Per Capita Income & $\$ 71,278$ & $\$ 45,256$ & $\$ 27,469$ \\
\hline \multicolumn{4}{|l|}{ Size or Quantity } \\
\hline Lockers & 14.2 & 63.1 & 98.2 \\
\hline Population (Pop.) & 156,386 & 681,403 & 806,872 \\
\hline Households (HH) & 57,842 & 272,153 & 313,740 \\
\hline Area (Mi.2) & 92.4 & 542.0 & 191.0 \\
\hline \multicolumn{4}{|l|}{ Densities } \\
\hline Lockers per Sq.Mi. & 0.15 & 0.12 & 0.51 \\
\hline Lockers per 1000 Pop. & 0.09 & 0.09 & 0.12 \\
\hline Lockers per $1000 \mathrm{HH}$ & 0.24 & 0.23 & 0.31 \\
\hline \multicolumn{4}{|l|}{ Access by Mode as \% Pop. } \\
\hline Walking (0.25-0.5) Mi.. & $3.9-17.1$ & $9.5-28.8$ & $14.7-41.2$ \\
\hline Biking (1.5-3.0 Mi.) & $73.0-97.8$ & $75.2-89.1$ & $92.0-96.2$ \\
\hline Driving (3.0-5.0 Mi.) & $97.8-100.0$ & $89.1-95.7$ & $96.2-97.0$ \\
\hline
\end{tabular}




\subsection{COMPUTER AND INTERNET ACCESS}

389 Figure 5 shows the results of the cluster analysis for the computer and internet access category.

390 The spatial distribution of the clusters here appears to be somewhat more dispersed than those

391 generated by the income category, although there does appear to be some correlation between

392 Clusters 1 and 3 in Figure 5 and Clusters 1 and 3 in Figure 4.

393

394

395

396

397

398

399

400

401

402

403

404

405

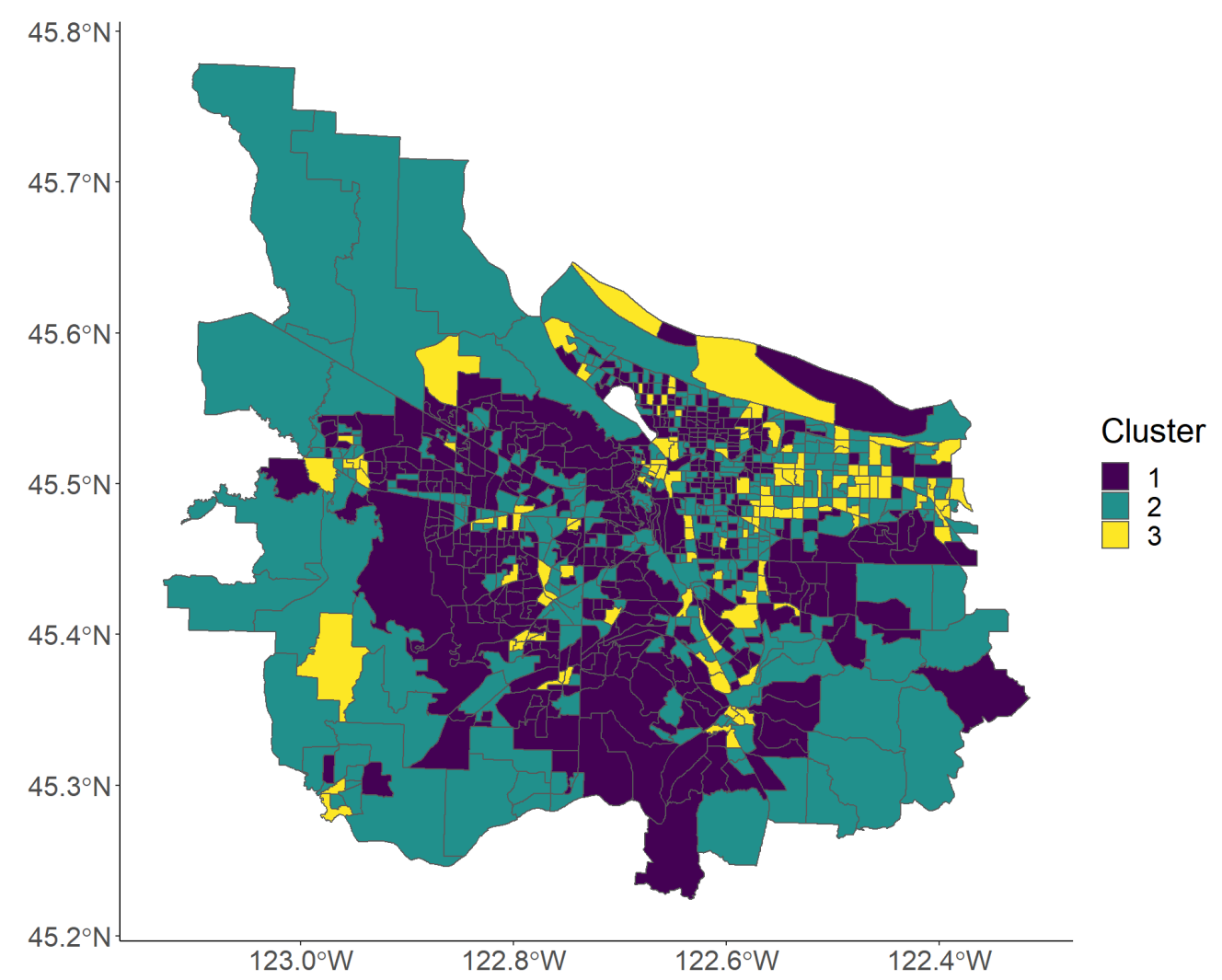

Figure 5: Internet and computer access cluster results.

Table 3 highlights the variables that most characterize the computer and internet access clusters and their values. Households in Cluster 1 were most likely to have access to a computer and broadband internet service. Households in Cluster 3 were least likely to have access to a computer or broadband service and were far more likely to have no access to internet at all relative to Cluster 1 or Cluster 2. Recalling the observation of the minor correlations with Clusters 1 and 3 in the Income category, these results suggest lower income populations have less access to computers and internet compared to higher income populations. Cluster 2 appeared most likely to have cell only based internet access, although the difference from Cluster 3 was very small. Considering much of the Cluster 2 area is located farther from the city center, this 
406 finding may be partially explained by service area limits for broadband internet, i.e., the option

407 of broadband may not exist in outlying areas.

408 Table 3: Internet access cluster characteristics

\begin{tabular}{|c|c|c|c|}
\hline Key Variables & $\begin{array}{l}\text { Cluster } 1 \\
\text { "High" }\end{array}$ & $\begin{array}{l}\text { Cluster } 2 \\
\text { "Medium" }\end{array}$ & $\begin{array}{l}\text { Cluster } 3 \\
\text { "Low" }\end{array}$ \\
\hline$\%$ HH with Computer & 97.9 & 93.4 & 82.3 \\
\hline$\%$ HH with Broadband & 94.3 & 85.0 & 71.1 \\
\hline$\%$ HH with Cell Only & 5.9 & 9.0 & 8.9 \\
\hline$\% \mathrm{HH}$ without Internet & 3.9 & 10.4 & 23.7 \\
\hline \multicolumn{4}{|l|}{ Size or Quantity } \\
\hline Lockers & 73.6 & 68.8 & 33.0 \\
\hline Population (Pop.) & 834,530 & 594,030 & 216,101 \\
\hline Households (HH) & 318,592 & 235,225 & 89,918 \\
\hline Area (Mi.2) & 293.7 & 468.7 & 63.0 \\
\hline \multicolumn{4}{|l|}{ Densities } \\
\hline Lockers per Sq.Mi. & 0.25 & 0.15 & 0.52 \\
\hline Lockers per 1000 Pop. & 0.09 & 0.12 & 0.15 \\
\hline Lockers per $1000 \mathrm{HH}$ & 0.23 & 0.29 & 0.37 \\
\hline \multicolumn{4}{|c|}{ Access by Mode as \% Pop. } \\
\hline Walking (0.25-0.5) Mi.. & $7.8-26.0$ & $14.7-40.0$ & $16.8-46.7$ \\
\hline Biking (1.5-3.0 Mi.) & $78.2-93.9$ & $85.8-91.1$ & $95.4-97.8$ \\
\hline Driving (3.0-5.0 Mi.) & $93.9-98.3$ & $91.1-94.1$ & $97.8-98.1$ \\
\hline
\end{tabular}

410 Computer and internet access have been linked to income, and low access households may be

411 considered a disadvantaged group from an equity standpoint. The percentage of households

412 without internet access is highest in Cluster 3, at more than twice the percentage of the next

413 highest cluster (23.7\% vs. 10.4\% for Cluster 2 and 3.9\% for Cluster 1). Cluster 3 generally has

414 lower access to computers and internet services overall, relative to Clusters 1 and 2. However,

415 Cluster 3 appears to have the highest average concentration of lockers for all three measurement

416 units, particularly with respect to area. Cluster 3 may have greater access to the parcel lockers as

417 the percentage of its population within nearly all buffer distance ranges is greater than the

418 percentages for Cluster 1 or Cluster 2. This is a positive finding with regard to equity.

\subsection{TRANSPORTATION AND BUILT ENVIRONMENT}

420 The spatial distribution of the transportation and built environment category clusters is displayed

421 in Figure 6. The map shows the majority of Cluster 3 is in the center of the study area, which

422 generally corresponds to the downtown and inner eastside areas of Portland. Cluster 2 areas are

423 more dispersed around the region but seem to be located near major transportation routes.

424 Cluster 1 contains the most land area, consisting of most of the outlying regions and generally

425 surrounding the areas assigned to Clusters 2 and 3. 


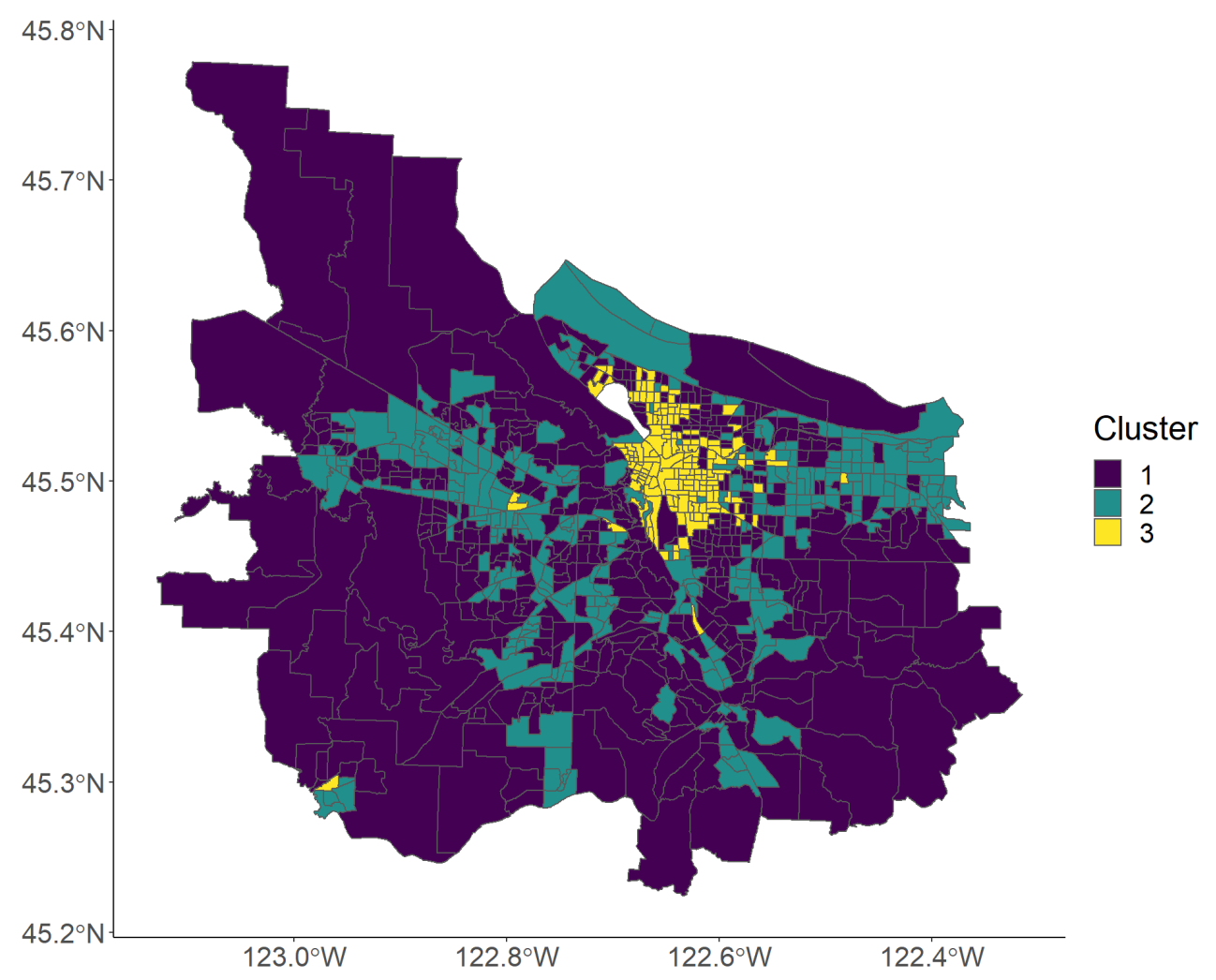

429 Several variables related to commute mode choice, housing unit type, and population density

430 were selected for display in Table 4 to quantify the primary characteristics of each cluster. These

431 variables generally showed the most variance among clusters. Housing unit types and population

432 density were included in this category as a representation of the built environment, which has

433 been shown to influence transportation choices (Cervero, 2002). When combining transport and

434 housing variables it is difficult to both succinctly and accurately label the clusters, nonetheless a

435 non-numerical "intuitive" description is added under each cluster.

437 Cluster 1 is characterized by a lower likelihood of walking or taking public transit to work,

438 relative to the other two clusters. Single detached housing was much more likely in Cluster 1 at

439 almost twice the percentages of Cluster 2 or Cluster 3. Correspondingly, multi-unit housing was

440 least likely in Cluster 1. Furthermore, population density was lowest in Cluster 1 relative to

441 Clusters 2 and 3. These findings align with the spatial distribution of the clusters shown in Figure

4426 , whereby Cluster 1 dominates the areas furthest from the population dense city center. 
443 The main characteristics of Cluster 2 are a tendency toward commuting by carpool, but not by

444 bicycle, relative to the other clusters. Cluster 2 also had the lowest average percentage of

445 workers working from home. Although the overall percentage of mobile houses is low in all

446 clusters, it is more than twice as high in Cluster 2 as in Cluster 1, the median cluster, and almost

447 ten times higher than in Cluster 3.

Table 4: Transportation and BE cluster characteristics

\begin{tabular}{|c|c|c|c|}
\hline Key Variables & $\begin{array}{c}\text { Cluster } 1 \\
\text { "Drive alone - } \\
\text { single housing" }\end{array}$ & $\begin{array}{c}\text { Cluster } 2 \\
\text { "Drive alone - } \\
\text { multi-unit" }\end{array}$ & $\begin{array}{c}\text { Cluster } 3 \\
\text { "Transit/active - } \\
\text { multi-unit" }\end{array}$ \\
\hline$\%$ Workers Drove Alone* & 72.4 & 68.3 & 45.6 \\
\hline$\%$ Workers Carpooled* & 8.3 & 11.8 & 5.3 \\
\hline$\%$ Workers Public Transit* & 5.4 & 8.8 & 17.3 \\
\hline$\%$ Workers Bicycled* & 2.3 & 1.4 & 10.9 \\
\hline$\%$ Workers Walked* & 1.9 & 3.4 & 10.7 \\
\hline$\%$ Workers Work from Home* & 8.8 & 5.1 & 8.9 \\
\hline$\%$ Housing as Single Detached & 86.1 & 39.9 & 44.5 \\
\hline$\%$ Housing as Multi-unit & 8.9 & 47.0 & 50.8 \\
\hline$\%$ Housing as Mobile & 1.9 & 3.9 & 0.4 \\
\hline Population Density (per $\mathrm{mi}^{2}{ }^{2}$ ) & 4948 & 6675 & 11922 \\
\hline \multicolumn{4}{|l|}{ Size or Quantity } \\
\hline Lockers & 72.7 & 70.6 & 32.2 \\
\hline Population (Pop.) & 794,218 & 623,453 & 226,990 \\
\hline Households (HH) & 289,326 & 247,956 & 106,453 \\
\hline Area (Mi.2) & 656.3 & 144.6 & 24.6 \\
\hline \multicolumn{4}{|l|}{ Densities } \\
\hline Lockers per Sq.Mi. & 0.11 & 0.49 & 1.31 \\
\hline Lockers per 1000 Pop. & 0.09 & 0.11 & 0.14 \\
\hline Lockers per $1000 \mathrm{HH}$ & 0.25 & 0.28 & 0.30 \\
\hline \multicolumn{4}{|l|}{ Access by Mode as \% Pop. } \\
\hline Walking $(0.25-0.5) \mathrm{Mi}$. & $6.2-21.4$ & $12.6-36.9$ & $26.9-68.3$ \\
\hline Biking (1.5-3.0 Mi.) & $74.2-88.3$ & $89.0-98.0$ & $98.0-98.8$ \\
\hline Driving (3.0-5.0 Mi.) & $88.3-94.5$ & $98.0-98.8$ & $98.8-100$ \\
\hline
\end{tabular}

*Aged 16 years or older

452 Cluster 3, primarily located in the central region of the city, is characterized by an appreciable 453 increase in population density relative the rest of the study area. Thus, it should not be surprising

454 that rates of public transit or active travel modes (walking or bicycling) of commuting to work

455 far outpaced rates elsewhere in the study area. The average expected number of lockers per

456 square mile is highest in Cluster 3 and lowest in Cluster 1 which tends to be more rural and has

457 the lowest population density. Cluster 3 also has a greater expected number of lockers per

458 population and per household, on average, although the differences between clusters are less

459 significant. The estimated percentage of the population in Cluster 3 within walking distance to an 
460 Amazon locker is nearly twice that of Cluster 2 and more than three times the percentage in

461 Cluster 1. Moreover, almost all of Cluster 3 is within 1.5 miles of an Amazon locker. As

462 expected, the percentage of Cluster 1 within the buffer zones is lowest for all three mode choices.

\section{6.4 NON-INCOME DEMOGRAPHICS}

465 Di Ciommo and Shiftan (2017) acknowledge age, educational level, and employment status are 466 related to income and car ownership. Youth and elderly who are non-drivers are more reliant on 467 public transportation and those with language barriers may be less likely to hold a driver's

468 license and have trouble navigating public transit. Additionally, race or ethnicity is frequently 469 considered in equity analyses as minorities often have lower relative incomes (Di Ciommo \& 470 Shiftan, 2017). Figure 7 displays a map of the non-income category cluster results. The map 471 shows most of the outlying areas and a strip through the center of the study region, west of the 472 downtown area, belong to Cluster 1.

473

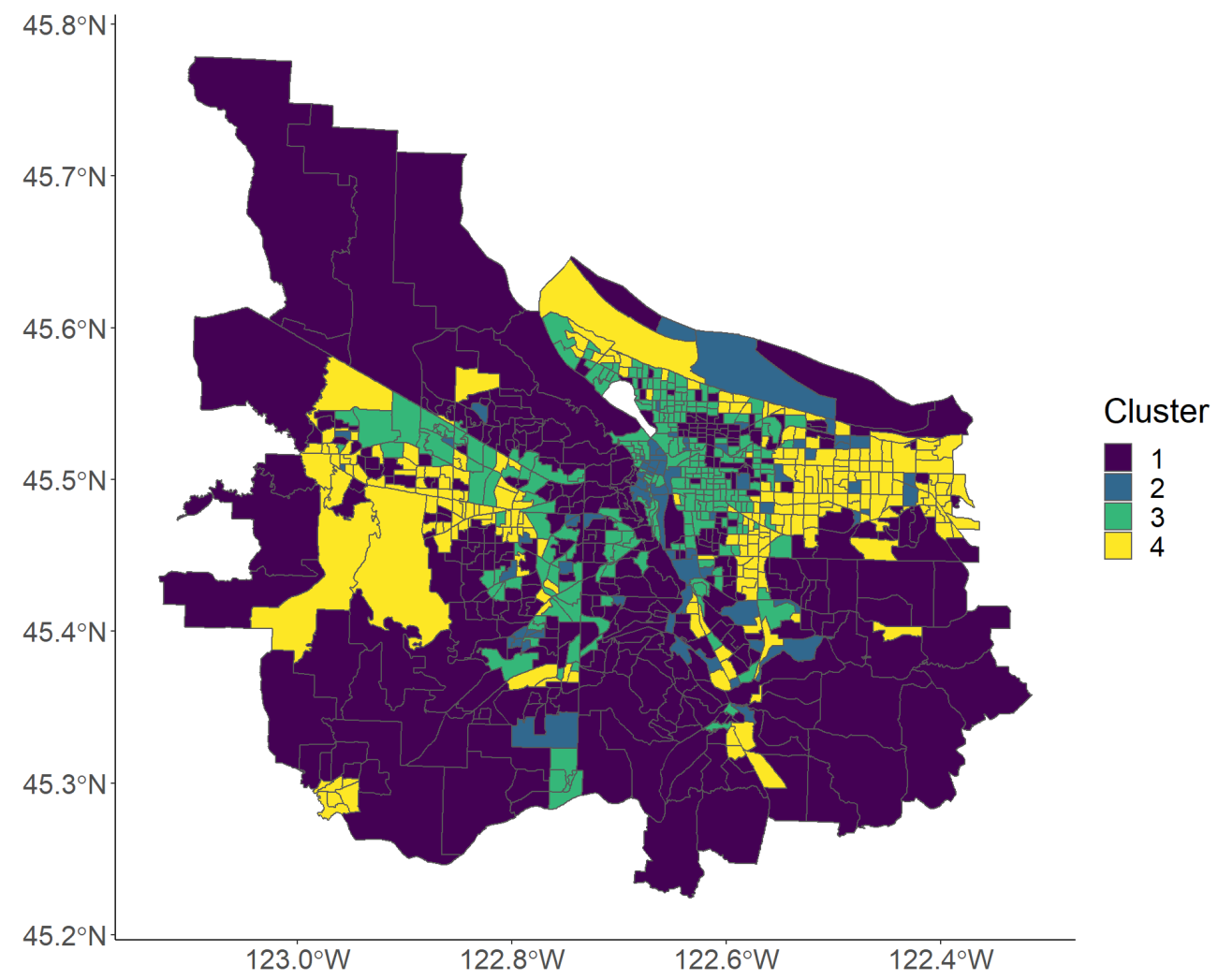

Figure 7: Non-Income Demographic cluster results. 
477 Cluster 2 is comprised of fewer block groups overall and appears to be dispersed among the 478 central and eastern portions of the study area. Block groups immediately east of the downtown 479 area appear to be predominantly of Cluster 3. Cluster 3 appears slightly more scattered in the 480 western half of the study area but seems to follow primary transportation routes. Cluster 4 block groups tend to be farther from the city center than those of Cluster 3 .

This category contained the largest number of variables and only those in which higher variances 484 were observed between clusters were selected for display in Table 5. Cluster 1 is characterized 485 by a much higher rate of owner-occupied housing. The housing units were less likely to have 486 only one occupant, but more likely to have four occupants compared to the other clusters.

487 Compared to Clusters 2 and 3, Cluster 1 was generally more likely to have multiple occupants in 488 a housing unit. The percent of the population who were age $0-9$ or 10-7 was also greater in 489 Cluster 1 than Cluster 2 or 3, but not greater than Cluster 4. In the adult age groups, Cluster 1 490 had the largest percentage of 45-64-year-olds but the smallest percentage of 18-29-year-olds on 491 average. This combination of age groups may indicate a high prevalence of families with 492 children. Moving to race and origin, Cluster 1 had the lowest percentages of Black or African 493 American and Hispanic or Latin-American in the population relative to all other clusters. The 494 population in Cluster 1 also tended to be more educated, with the lowest rate of non-high school graduates and higher rates of bachelor's and graduate or professional degrees. However, the differences in these rates compared to Cluster 3 were small. When many variables are present it

497 is difficult to both succinctly and accurately label the clusters, nonetheless a non-numerical "intuitive" description is added for each cluster.

A higher percentage of housing units with only one occupant was a prominent characteristic of Cluster 2. These block groups also tended to have the lowest rates of housing with three or more occupants compared to all other block groups. Additionally, Cluster 2 had the lowest percentage of the population aged 0-9 years but the highest percentage aged 65 or older, on average. There is a noticeably lower percentage of the population in the work force, and a higher percentage was indicated to have not worked in the past 12 months. These results seem to point to the presence of a higher percentage of retired persons in these block groups. 
Table 5: Non-Income cluster characteristics

Cluster 1

Key Variables

$\%$ Housing Occupied by Owner

$\%$ Housing with 1 Occupant

$\%$ Housing with 2 Occupants

$\%$ Housing with 3 Occupants

$\%$ Housing with 4 Occupants

$\%$ Housing with 5 Occupants

$\%$ Housing with 6 Occupants

$\%$ Housing with 7+ Occupants

\% Population Age 0-9

\% Population Age 10-17

\% Population Age 18-29

\% Population Age 30-44

$\%$ Population Age 45-54

$\%$ Population Age 65+

\% Pop. Black/African Am.

\% Pop. Hispanic/Latin-

American

\% Pop. Limited English Ability

\% Pop. < High School Degree*

\% Pop. Bachelor's Degree*

\% Pop. Graduate/Prof. Degree*

\% Population in Labor Force**

\% Population Did Not Work**

Size or Quantity

Lockers

Population (Pop.)

Households (HH)

Area (Mi.2)

Lockers per Sq.Mi.

Lockers per 1000 Pop.

Lockers per $1000 \mathrm{HH}$

Access by Mode as \% Pop.

Walking (0.25-0.5) Mi..

Biking (1.5-3.0 Mi.)

Driving (3.0-5.0 Mi.)
Densities

"Educated middle-

aged homeowners"

82.3

19.9

38.7

16.8

17.0

5.1

1.6

0.8

11.5

10.4

10.6

19.9

31.3

16.3

1.4

5.7

Cluster 2

"Older, less

workers"

"Educated,

younger workers"

40.6

54.1

31.2

6.9

5.0

1.9

0.4

0.6
5.2

5.2
4.5

15.3

19.0

26.3

29.9

4.7

8.2

\begin{tabular}{l|l|}
1.3 & 3.8 \\
\hline 3.9 & 8.0
\end{tabular}

31.4

22.0

66.8

29.8

\begin{tabular}{l}
54.9 \\
\hline
\end{tabular}

51.7

51.7

644,447

238,510

588.6

\begin{tabular}{r|}
44.9 \\
\\
20.4 \\
100,009 \\
53,774 \\
33.4 \\
\hline
\end{tabular}

0.09

0.08

0.22

3-17.4

$4.3-17.4$
$67.5-86.3$

86.3-93.6

*Aged 25 years or older; **Aged 16 years or older

33.9

37.2

Cluster 4

"Young, Hispanic,

Latin-American"

\begin{tabular}{r|r}
45.4 & 51.9 \\
\hline
\end{tabular}

25.2

29.8

\begin{tabular}{r|r}
14.9 & 16.8 \\
\hline 9.9
\end{tabular}

9.9

\begin{tabular}{l|l}
2.8 & 8.1 \\
\hline 0.9 & 3.9 \\
\hline 0.4 & 2.3
\end{tabular}

\begin{tabular}{r|r}
0.9 & 3.9 \\
\hline 9.4 & 2.3 \\
\hline
\end{tabular}

\begin{tabular}{l|r}
\hline 9.4 & 14.3 \\
\hline
\end{tabular}

\begin{tabular}{ll}
5.7 & 10.5 \\
\hline
\end{tabular}

\begin{tabular}{l|l}
\hline 22.5 & 17.4 \\
\hline 30.8 &
\end{tabular}

\begin{tabular}{l|l}
30.8 & 24.1 \\
\hline
\end{tabular}

\begin{tabular}{r|r}
21.9 & 23.0 \\
\hline
\end{tabular}

\begin{tabular}{r|r}
9.8 & 10.8
\end{tabular}

\begin{tabular}{l|l}
\hline 4.8 & 4.9 \\
\hline
\end{tabular}

\begin{tabular}{l}
8.8 \\
\hline
\end{tabular}

\begin{tabular}{l|l}
1.7 & 8.6 \\
\hline
\end{tabular}

\begin{tabular}{l|l}
1.7 & 8.6 \\
\hline 4.7 & 17.0 \\
\hline
\end{tabular}

\begin{tabular}{l|r}
\hline 32.8 & 16.6 \\
\hline
\end{tabular}

\begin{tabular}{r|r}
32.8 & 6.9
\end{tabular}

76.8
20.6

\begin{tabular}{l|l}
76.8 & 67.6 \\
\hline 20.6 & 30.4
\end{tabular}


511 Cluster 3 appears to have higher percentages of 18-29-year-olds and 30-44-year-olds relative to

512 all other clusters. The population in these block groups also tend to be more educated, with

513 higher rates of bachelor's and graduate or professional degrees than Cluster 2 or Cluster 4. Also,

514 on average, the percentage of the population in the workforce was highest for Cluster 3 while the

515 percent of the population that did not work was the lowest compared to all other Clusters.

516 Together, these characteristics may indicate a higher presence of younger working adults.

518 In Cluster 4, a few characteristics are quite pronounced. For example, the percentage of housing 519 units with five, six, or seven or more occupants is much higher relative to the other clusters. In 520 addition, the percentages of the population with Hispanic or Latin-American origins, limited 521 English speaking abilities, or attaining less than a high school (or equivalent) degree are 522 significantly higher compared to the other clusters. On average, the population in Cluster 4 has 523 the lowest rates of bachelor's and graduate or professional degrees and the highest percentages of 524 children aged 0-9 years and 10-17 years. These characteristics seem to indicate a higher 525 prevalence of larger families and population of Hispanic or Latin-American origin.

527 Cluster 3 is shown having the highest average locker density with respect to area, but Cluster 2 528 has the highest average density with respect to both population and households. The lowest 529 average locker densities for all three measurement units exist in Cluster 1. Cluster 2 is 530 characterized by a couple of factors that may contribute to transportation disadvantage, including 531 greater percentages of people aged 65 or older or those who do not work as compared to the 532 other clusters. Cluster 4 exhibits a greater number of demographic qualities that may contribute 533 to transportation disadvantages. Cluster 4 has the highest percentage of young children (aged 0-9 534 years), and much higher percentages of people with Hispanic or Latin-American origin or with 535 limited English language abilities. This cluster also demonstrated the lowest education levels on 536 average, with the highest proportion of people with less than a high school degree (and the 537 lowest proportions of people with bachelor's or graduate degrees). For this equity category, it 538 appears that Cluster 4 should be prioritized.

540 Regarding percentages of the population in each cluster within the walking, biking, and driving 541 locker buffers, the lowest percentages are observed in Cluster 1 for all modes, followed by 
542 Cluster 4. Cluster 2 and Cluster 3 demonstrate the highest population percentages within the

543 locker buffers, reaching almost 100\% within a 3-mile radius. It appears that the distribution of

544 Amazon lockers in Cluster 4 is not on par with the distribution in Cluster 2 or Cluster 3.

545 Additional focus should be given to Cluster 4 with when considering locations for new locker

546 facilities if locker access equity is a policy goal.

548 Mail and package distribution are considered a basic service. Access to basic goods, services, 549 and activities is a key component in accessibility-based transportation equity evaluations 550 (Litman, 2002). In the postal service literature, the concept of universal service for post and 551 packages has been frequently discussed (Cohen et al., 1993; Cremer et al., 2000; De Donder et

552 al., 2002). Universal postal service includes accessibility for all, quality of service, and 553 reasonableness of rates, with an overall goal of avoiding major access differences via differential 554 pricing and product offerings that create conditions that result in a "market failure". In the 555 transportation literature the term market failure implies a situation when a minimum level of 556 accessibility or mobility that should be available to all is not met (Button, 2005). The idea of 557 avoiding market failure in transportation has many similarities with the concept of universal 558 postal service.

560 Regarding locker accessibility, a market failure can be defined as situations where locker 561 locations respond solely to customer demand and purchasing power with no coverage of 562 populations that need affordable and/or convenient locker access. Amazon is a private, profit563 seeking entity, and the placement of lockers responds to customer demands and the company's 564 overall competitive strategy, and these goals may not necessarily match the allocation of lockers 565 based on equity or need considerations. It should be the role of policy makers and transportation 566 agencies to analyze whether policies or the allocation of resources to improve locker 567 accessibility based on need and/or equity considerations are justified.

569 Parcel policies should also take into account that there are four basic types of parcel locker 570 systems depending on carrier and public access characteristics: a) Open or common carrier 571 parcel locker systems which can be utilized by different logistics operators or e-commerce 
572 companies and may be run by an external non-profit entity like a city or metropolitan agency.

573 These lockers are usually located in public spaces and can be utilized by any potential customer.

574 b) Closed locker systems which are operated and managed by one business, stakeholder, or

575 consortium. In closed systems, only the owner or operator typically utilizes the locker (rival

576 companies do not have access). These lockers are located on private property owned by the

577 owner of the locker or through access granted via a contract (e.g., Amazon lockers located at

578 convenience stores) but they can be utilized by any potential customer. The third class of locker

579 system c) is usually located inside multi-unit residential apartment units. This third type of

580 system is usually located indoor and run by the building or property manager and can be utilized

581 by different carriers or logistic operators. However, they have restricted (no public) access since

582 only residents or property owners can utilize the indoor lockers. In cases a) and b) public access

583 is not restricted. Finally, case d) is a closed system with restricted customer access that could be

584 utilized in some business settings. The discussion and focus of this research is on cases a) and b)

585 where there is unrestricted public access, though at the moment only type b) is available in

586 Portland and type a) could be promoted by policy makers where needed.

588 The equity spatial analysis presented in this research has direct policy implications since it can

589 guide the placement of incentives to locate additional (open) lockers in urban areas, for example

590 installing supplementary common carrier (open) public parcel lockers in transit stations where

591 they are needed the most to fill an equity or accessibility gap (Keeling et al., 2021). Common

592 carrier lockers could then serve public agencies' accessibility and equity goals, facilitating

593 deliveries for those who are transportation disadvantaged or time poor.

595 Policy makers could also use the proposed methodology to monitor the ongoing installation of 596 lockers across the urban area. In Poland, the capital Warsaw with 600 lockers (Wilczek, 2021), 597 has a much higher density of lockers per capita than Portland, almost 4.5 times more lockers per 598 capita. Based on Warsaw's figures, it is likely that more lockers will be installed in the future in 599 the Portland metropolitan region. Given the dramatic growth of e-commerce the locker market is 600 not yet mature. 
603 E-commerce is growing rapidly, and it is critical that different populations have access to

604 efficient and environmentally friendly last mile delivery options like automated lockers. This

605 research presents a novel approach utilizing cluster analysis to evaluate locker distribution

606 accessibility and equity metrics. Overall, a large percentage of the population can access

607 Amazon lockers because they tend to be located in convenience or other small format retail

608 stores, close to arterial roads, on land zoned for mixed-use commercial and residential, and in

609 areas of higher population and employment density. In terms of accessibility by mode, lockers

610 are accessible by automobile for the vast majority of the population in the Portland metropolitan

611 region. The share of the population that can access lockers by walking is significantly smaller

612 and this may present a challenge for non-driver populations.

614 Regarding equity, clusters in the income and computer and internet access categories appear to

615 have equitable access to parcel lockers. However, the data suggests that there is less access to

616 parcel lockers for Hispanics, people with low education levels, or people who have limited

617 English language abilities. Black and African Americans did not clearly fall into one cluster, but

618 this may be due to the relatively low number of Black and African Americans in the Portland

619 metropolitan area.

621 Ancillary benefits of additional locker locations could also include a reduction in delivery

622 vehicle miles traveled as well as reduced energy consumption and emissions. More policy

623 implications can be found by increasing the spatial resolution, e.g., an inspection of the bottom

624 ten block groups when ranked in order of highest to lowest number of lockers per population and

625 per households revealed nine of them belong to the low-income cluster. Another policy

626 implication is that equity metrics differ widely based on the units utilized, for example lockers

627 per area, per population, or per household. Suburban low-density areas have the lowest levels of

628 lockers per area or population, but tend to be inhabited by educated, higher income homeowners.

629 Hispanics tend to be in more dense areas in terms of population but with lower density of lockers

630 per population when compared to similarly dense areas. Given the larger size of Hispanic

631 households the equity metrics are sharper when considering equity metrics per population instead

632 of per household. 
633 The equity spatial analysis presented in this research has direct policy implications since it can 634 guide monitoring of the parcel locker system as well as the placement of resources or common 635 carrier public parcel lockers where they are needed the most to fill an equity or accessibility gap 636 or reduce a potential market failure. Policy makers and public agencies could use the proposed 637 methodology to monitor locker accessibility and equity goals and recognize potential market 638 failures. In this research parcel locker systems are classified into four basic types depending on 639 carrier and public access characteristics. Policy makers should also monitor how locker type 640 evolves over time, since closed or restricted locker systems do not bring the same advantages in 641 terms of sustainability or equity respectively.

643 This research also introduces the concept of market failure in the parcel locker market. Lower 644 income and underserved populations engage less in e-commerce and home deliveries, and it is 645 possible that in addition to income barriers, there are other barriers like accessibility to 646 affordable and conveniently located lockers that may accentuate e-commerce inequities. This is 647 an issue that so far has not received enough attention in the parcel locker literature.

649 Lack of access to essential services such as food has given rise to concepts like food deserts.

650 Similarly, lack of access to e-commerce and efficient last mile delivery systems can be studied in 651 future research efforts as ancillary services to bridge the digital divide and barriers that impede 652 access to new products and services. The traditional concept of accessibility can be broadened to 653 include access to parcel lockers, i.e. adding access to lockers to expand the concept of home 654 based accessibility for e-commerce products and services first introduced by Figliozzi and 655 Unnikrishnan (2021). This is relevant as governments foster e-commerce access, for example to 656 provide touchless and safe deliveries during the COVID-19 crisis and beyond, avoiding or 657 reducing social contact in stores or with home delivery personnel.

659 The main ideas and methods utilized in this research are likely transferable to other urban areas 660 but not the specific findings associated to the spatial distribution of lockers and population 661 characteristics. Future research efforts are recommended in cities or regions with a different 662 spatial or sociodemographic composition. 


\section{REFERENCES}

Amazon. (2019). Turn your location into an Amazon Hub destination. https://go.thehubamazon.com/amazon-hub-locker

Baddeley, A., Rubak, E., \& Turner, R. (2015). Spatial Point Patterns: Methodology and Applications with R (1st ed.). Chapman and Hall/CRC. https://doi.org/10.1201/b19708

Blanc, B., \& Figliozzi, M. (2016). Modeling the Impacts of Facility Type, Trip Characteristics, and Trip Stressors on Cyclists' Comfort Levels Utilizing Crowdsourced Data. Transportation Research Record: Journal of the Transportation Research Board, 2587(1), 100-108. https://doi.org/10.3141/2587-12

Button, K. J. (2005). Market and government failures in transportation. In Handbook of transport strategy, policy and institutions. Emerald Group Publishing Limited.

Cao, X. J., Xu, Z., \& Douma, F. (2012). The interactions between e-shopping and traditional instore shopping: An application of structural equations model. Transportation, 39(5), 957974.

Cervero, R. (2002). Built environments and mode choice: Toward a normative framework. Transportation Research Part D: Transport and Environment, 7(4), 265-284. https://doi.org/10.1016/S1361-9209(01)00024-4

Chen, Q., Conway, A., \& Cheng, J. (2017). Parking for residential delivery in New York City: Regulations and behavior. Transport Policy, 54, 53-60.

Cidell, J. (2010). Concentration and decentralization: The new geography of freight distribution in US metropolitan areas. Journal of Transport Geography, 18(3), 363-371. https://doi.org/10.1016/j.jtrangeo.2009.06.017 
Cohen, R. H., Ferguson, W. W., Xenakis, S. S., \& Kendall, R. L. (1993). Rural Delivery and the Universal Service Obligation: A Quantitative Investigation. In Regulation and the nature of postal and delivery services (pp. 161-177). Springer.

Cosgrove, E. (2019, June 27). Amazon adds counter parcel pickup in 100 Rite Aid stores. Supply Chain Dive. https:/www.supplychaindive.com/news/Rite-aid-amazon-counter/557775/

Cremer, H., Laffont, J.-J., \& Grimaud, A. (2000). The Cost of Universal Service in the Postal Sector. In M. A. Crew \& P. R. Kleindorfer (Eds.), Current Directions in Postal Reform (pp. 47-68). Springer US. https://doi.org/10.1007/978-1-4615-4481-4_3

Crocco, F., Eboli, L., \& Mazzulla, G. (2013). Individual Attitudes and Shopping Mode Characteristics Affecting the Use of E-Shopping and Related Travel. Transport and Telecommunication Journal, 14(1), 45-56. https://doi.org/10.2478/ttj-2013-0006

De Blasio, G. (2008). Urban-Rural Differences in Internet Usage, e-Commerce, and e-Banking: Evidence from Italy. Growth and Change, 39(2), 341-367. https://doi.org/10.1111/j.1468-2257.2008.00422.x

De Donder, P., Cremer, H., \& Rodriguez, F. (2002). Access Pricing and Parcels Delivery. In Postal and Delivery Services (pp. 49-69). Springer.

Deutsch, Y., \& Golany, B. (2018). A parcel locker network as a solution to the logistics last mile problem. International Journal of Production Research, 56(1-2), 251-261. https://doi.org/10.1080/00207543.2017.1395490

Di Ciommo, F., \& Shiftan, Y. (2017). Transport equity analysis. Transport Reviews, 37(2), 139151. https://doi.org/10.1080/01441647.2017.1278647

Diaz-Varela, E. R., Vazquez-Gonzalez, I., Marey-Pérez, M. F., \& Álvarez-López, C. J. (2011). Assessing methods of mitigating wildlife-vehicle collisions by accident characterization 
and spatial analysis. Transportation Research Part D: Transport and Environment, 16(4), 281-287. https://doi.org/10.1016/j.trd.2011.01.002

du Preez, D., Zuidgeest, M., \& Behrens, R. (2019). A quantitative clustering analysis of paratransit route typology and operating attributes in Cape Town. Journal of Transport Geography, 80, 102493. https://doi.org/10.1016/j.jtrangeo.2019.102493

Edwards, J., McKinnon, A., Cherrett, T., McLeod, F., \& Song, L. (2009). The impact of failed home deliveries on carbon emissions: Are collection/delivery points environmentallyfriendly alternatives? 102-108.

https://pdfs.semanticscholar.org/765b/561a7c336395f692ecddd3ee58f90c603787.pdf

Fang, J., Giuliano, G., \& Wu, A.-M. (2019). The Spatial Dynamics of Amazon Lockers in Los Angeles County (MF-5.4c). Article MF-5.4c. https://trid.trb.org/view/1724638

Farag, S., Schwanen, T., Dijst, M., \& Faber, J. (2007). Shopping online and/or in-store? A structural equation model of the relationships between e-shopping and in-store shopping. Transportation Research Part A: Policy and Practice, 41(2), 125-141. https://doi.org/10.1016/j.tra.2006.02.003

FHWA. (2018). NHTS Brief: Changes in Online Shopping Trends. Federal Highway Administration FHWA. https://nhts.ornl.gov/assets/NHTSBriefOnlineShopping081018.pdf

Figliozzi, M., \& Unnikrishnan, A. (2021). Home-deliveries before-during COVID-19 lockdown: Accessibility, environmental justice, equity, and policy implications. Transportation Research Part D: Transport and Environment, 93, 102760. https://doi.org/10.1016/j.trd.2021.102760 
Haustein, S., \& Nielsen, T. A. S. (2016). European mobility cultures: A survey-based cluster analysis across 28 European countries. Journal of Transport Geography, 54, 173-180. https://doi.org/10.1016/j.jtrangeo.2016.05.014

Holsenbeck, K. F. (2018, June 21). Everything you need to know about Amazon Hub Locker. Amazon.Com. https://www.amazon.com/primeinsider/tips/amazon-locker-qa.html

Husson, F., \& Josse, J. (2020). missMDA: Handling Missing Values with Multivariate Data Analysis (1.18) [Computer software]. https://CRAN.R-project.org/package=missMDA

INPOST. (2021). Quick Send. Send parcels quickly and conveniently with InPost. Send Parcels Quickly and Conveniently! https://inpost.pl/SzybkieNadania/

Iwan, S., Kijewska, K., \& Lemke, J. (2016). Analysis of Parcel Lockers' Efficiency as the Last Mile Delivery Solution - The Results of the Research in Poland. Transportation Research Procedia, 12, 644-655. https://doi.org/10.1016/j.trpro.2016.02.018

Kedia, Kusumastuti, \& Nicholson. (2019). Establishing collection and delivery points to encourage the use of active transport: A case study in New Zealand using a consumercentric approach. Sustainability, 11(22), 6255. https://doi.org/10.3390/su11226255

Keeling, K., Schaefer, J. S., \& Figliozzi, M. (2021). Accessibility and Equity Analysis of Common Carrier Parcel Lockers at Transit Facilities in Portland, Oregon. Transportation Research Record: Journal of the Transportation Research Board, Forthcoming.

Lachapelle, U., Burke, M., Brotherton, A., \& Leung, A. (2018). Parcel locker systems in a car dominant city: Location, characterisation and potential impacts on city planning and consumer travel access. Journal of Transport Geography, 71, 1-14. https://doi.org/10.1016/j.jtrangeo.2018.06.022 
Lagorio, A., \& Pinto, R. (2020). The parcel locker location issues: An overview of factors affecting their location. 414-421.

Lee, H., Chen, M., Pham, H. T., \& Choo, S. (2019). Development of a decision making system for installing unmanned parcel lockers: Focusing on residential complexes in Korea. KSCE Journal of Civil Engineering, 23(6), 2713-2722. https://doi.org/10.1007/s12205019-1398-y

Lemke, J., Iwan, S., \& Korczak, J. (2016). Usability of the parcel lockers from the customer perspective - the research in Polish cities. Transportation Research Procedia, 16, 272 287. https://doi.org/10.1016/j.trpro.2016.11.027

Litman, T. (2002). Evaluating transportation equity. World Transport Policy \& Practice, 8(2), $50-65$.

Lunden, I. (2018, July 13). Amazon's share of the US e-commerce market is now 49\%, or 5\% of all retail spend. TechCrunch. https://social.techcrunch.com/2018/07/13/amazons-shareof-the-us-e-commerce-market-is-now-49-or-5-of-all-retail-spend/

Morganti, E., Dablanc, L., \& Fortin, F. (2014). Final deliveries for online shopping: The deployment of pickup point networks in urban and suburban areas. Research in Transportation Business \& Management, 11, 23-31. https://doi.org/10.1016/j.rtbm.2014.03.002

Morganti, E., Seidel, S., Blanquart, C., Dablanc, L., \& Lenz, B. (2014). The impact of ecommerce on final deliveries: Alternative parcel delivery services in France and Germany. Transportation Research Procedia, 4, 178-190.

https://doi.org/10.1016/j.trpro.2014.11.014 
Moroz, M., \& Polkowski, Z. (2016). The Last Mile Issue and Urban Logistics: Choosing Parcel Machines in the Context of the Ecological Attitudes of the Y Generation Consumers Purchasing Online. Transportation Research Procedia, 16, 378-393. https://doi.org/10.1016/j.trpro.2016.11.036

Oliveira, L. K. de, Morganti, E., Dablanc, L., \& Oliveira, R. L. M. de. (2017). Analysis of the potential demand of automated delivery stations for e-commerce deliveries in Belo Horizonte, Brazil. Research in Transportation Economics, 65, 34-43. https://doi.org/10.1016/j.retrec.2017.09.003

Oliveira, L. K. de, Oliveira, R. L. M. de, Sousa, L. T. M. de, Caliari, I. de P., Nascimento, C. de O. L., Oliveira, L. K. de, Oliveira, R. L. M. de, Sousa, L. T. M. de, Caliari, I. de P., \& Nascimento, C. de O. L. (2019). Analysis of accessibility from collection and delivery points: Towards the sustainability of the e-commerce delivery. Urbe. Revista Brasileira de Gestão Urbana, 11. https://doi.org/10.1590/2175-3369.011.e20190048

Rodrigue, J.-P. (2020). The distribution network of Amazon and the footprint of freight digitalization. Journal of Transport Geography, 88, 102825. https://doi.org/10.1016/j.jtrangeo.2020.102825

Schweitzer, L. (2006). Environmental justice and hazmat transport: A spatial analysis in southern California. Transportation Research Part D: Transport and Environment, 11(6), 408421.

SCTLC. (2018). Evaluation of Sound Transit Train Stations and Transit Oriented Development Areas for Common Carrier Locker Systems. Supply Chain Transportation \& Logistics Center, University of Washington. 
http://depts.washington.edu/sctlctr/research/publications/evaluation-sound-transit-trainstations-and-transit-oriented-development-areas

Small, R. (2016, April 18). You are Here: Metro snapshop of how Portland gets around. https://www.oregonmetro.gov/news/you-are-here-snapshot-how-portland-region-getsaround

US Census Bureau. (2019, September 16). Glossary. The United States Census Bureau. https://www.census.gov/programs-surveys/geography/about/glossary.html

Vakulenko, Y., Hellström, D., \& Hjort, K. (2018). What's in the parcel locker? Exploring customer value in e-commerce last mile delivery. Journal of Business Research, 88, 421427. https://doi.org/10.1016/j.jbusres.2017.11.033

Verlinde, S., De Maere, B., Rai, B., \& Macharis, C. (2019, June 14). What is the most environmentally sustainable solution: Home deliveries or locker deliveries? International Conference on City Logistics, Dubrovnik.

Vikingson, A., \& Bengtsson, C. (2015). Exploring and evaluating the parcel locker: A Swedish consumer perspective [Lund University]. http://lup.lub.lu.se/luur/download?func=downloadFile\&recordOId=5462554\&fileOId=54 62562

Viu-Roig, M., \& Alvarez-Palau, E. J. (2020). The Impact of E-Commerce-Related Last-Mile Logistics on Cities: A Systematic Literature Review. Sustainability, 12(16), 6492. https://doi.org/10.3390/su12166492

Wilczek, M. (2021, July 6). Poland's parcel locker giant launches one-hour grocery delivery app. Notes From Poland. https://notesfrompoland.com/2021/07/06/polands-parcel-lockergiant-launches-one-hour-grocery-delivery-app/ 


\section{APPENDIX}

Table A. 1: Descriptive statistics for all ACS variables.

\begin{tabular}{|c|c|c|c|c|c|c|c|}
\hline Income Variables: & Min & 15th Perc & Median & 85th Perc & Max & Mean & St. Dev \\
\hline $\begin{array}{l}\text { Median Housing Unit Value } \\
\text { (Million \$) }\end{array}$ & 0.01 & 0.25 & 0.36 & 0.53 & 0.99 & 0.39 & 0.15 \\
\hline Average HH Income (Million \$) & 0.01 & 0.06 & 0.09 & 0.13 & 0.36 & 0.10 & 0.04 \\
\hline Median HH Income (Million \$) & 0.01 & 0.05 & 0.07 & 0.11 & 0.23 & 0.08 & 0.03 \\
\hline Per Capita Income (Million \$) & 0.01 & 0.02 & 0.04 & 0.05 & 0.12 & 0.04 & 0.02 \\
\hline $\begin{array}{l}\text { Computer and Internet Access } \\
\text { Variables: }\end{array}$ & Min & 15th Perc & Median & 85th Perc & $\operatorname{Max}$ & Mean & St. Dev \\
\hline$\% \mathrm{HH}$ with Computer & 0.62 & 0.88 & 0.96 & 1.00 & 1.00 & 0.94 & 0.06 \\
\hline $\begin{array}{l}\text { \% HH with Internet (All Sub. } \\
\text { Types) }\end{array}$ & 0.29 & 0.79 & 0.90 & 0.96 & 1.00 & 0.88 & 0.09 \\
\hline \% HH with Broadband Sub. & 0.29 & 0.79 & 0.90 & 0.96 & 1.00 & 0.88 & 0.09 \\
\hline$\%$ HH with Dial-up Only Sub. & 0.00 & 0.00 & 0.00 & 0.01 & 0.10 & 0.00 & 0.01 \\
\hline$\%$ HH with Cell Only Sub. & 0.00 & 0.02 & 0.06 & 0.13 & 0.39 & 0.07 & 0.06 \\
\hline$\%$ HH with Satellite Only Sub. & 0.00 & 0.00 & 0.00 & 0.01 & 0.22 & 0.01 & 0.01 \\
\hline $\begin{array}{l}\text { \% HH with Other Internet Only } \\
\text { Sub. }\end{array}$ & 0.00 & 0.00 & 0.00 & 0.00 & 0.08 & 0.00 & 0.01 \\
\hline \% HH with Internet (No Sub.) & 0.00 & 0.00 & 0.02 & 0.06 & 0.44 & 0.03 & 0.04 \\
\hline$\% \mathrm{HH}$ without Internet & 0.00 & 0.02 & 0.07 & 0.17 & 0.56 & 0.09 & 0.08 \\
\hline Transportation-BE Variables: & Min & 15th Perc & Median & 85th Perc & Max & Mean & St. Dev \\
\hline \% Workers Drove Alone* & 0.06 & 0.52 & 0.68 & 0.80 & 0.98 & 0.66 & 0.14 \\
\hline$\%$ Workers Carpooled* & 0.00 & 0.03 & 0.08 & 0.15 & 0.64 & 0.09 & 0.06 \\
\hline$\%$ Workers Public Transit* & 0.00 & 0.01 & 0.07 & 0.16 & 0.59 & 0.09 & 0.08 \\
\hline$\%$ Workers Bicycled* & 0.00 & 0.00 & 0.01 & 0.09 & 0.32 & 0.04 & 0.05 \\
\hline \% Workers Walked* & 0.00 & 0.00 & 0.02 & 0.08 & 0.55 & 0.04 & 0.07 \\
\hline \% Workers Work from Home* & 0.00 & 0.02 & 0.07 & 0.13 & 0.35 & 0.08 & 0.05 \\
\hline$\%$ Workers Other Trans. ${ }^{*}$ & 0.00 & 0.00 & 0.00 & 0.02 & 0.21 & 0.01 & 0.02 \\
\hline$\%$ Workers Taxi* & 0.00 & 0.00 & 0.00 & 0.00 & 0.17 & 0.00 & 0.01 \\
\hline$\%$ Workers Motorcycle* & 0.00 & 0.00 & 0.00 & 0.01 & 0.07 & 0.00 & 0.01 \\
\hline$\%$ Housing as Single Detached & 0.00 & 0.28 & 0.69 & 0.95 & 1.00 & 0.63 & 0.29 \\
\hline$\%$ Housing as Single Attached & 0.00 & 0.00 & 0.03 & 0.11 & 0.45 & 0.05 & 0.07 \\
\hline$\%$ Housing as Multi-unit & 0.00 & 0.00 & 0.23 & 0.61 & 1.00 & 0.29 & 0.28 \\
\hline$\%$ Housing as Mobile & 0.00 & 0.00 & 0.00 & 0.03 & 0.81 & 0.02 & 0.07 \\
\hline $\begin{array}{l}\text { Population Density (Thous. per } \\
\text { mi.2) }\end{array}$ & 0.03 & 2.72 & 6.03 & 10.30 & 59.92 & 6.79 & 5.28 \\
\hline
\end{tabular}

\begin{tabular}{l|l|l|l|l|l|l|l}
\hline $\begin{array}{l}\text { Non-income Demographic } \\
\text { Variables: }\end{array}$ & Min & 15th Perc & Median & 85th Perc & Max & Mean & St. Dev \\
\hline
\end{tabular}




\begin{tabular}{|c|c|c|c|c|c|c|c|}
\hline$\%$ Housing Occupied & 0.69 & 0.90 & 0.96 & 1.00 & 1.00 & 0.95 & 0.05 \\
\hline$\%$ Housing Occupied by Owner & 0.00 & 0.33 & 0.65 & 0.88 & 1.00 & 0.61 & 0.25 \\
\hline$\%$ Housing with 1 Occupant & 0.00 & 0.15 & 0.25 & 0.40 & 0.98 & 0.28 & 0.14 \\
\hline$\%$ Housing with 2 Occupants & 0.00 & 0.25 & 0.35 & 0.45 & 0.71 & 0.35 & 0.10 \\
\hline$\%$ Housing with 3 Occupants & 0.00 & 0.08 & 0.15 & 0.23 & 0.45 & 0.16 & 0.07 \\
\hline$\%$ Housing with 4 Occupants & 0.00 & 0.05 & 0.13 & 0.21 & 0.61 & 0.13 & 0.08 \\
\hline$\%$ Housing with 5 Occupants & 0.00 & 0.00 & 0.04 & 0.10 & 0.34 & 0.05 & 0.05 \\
\hline$\%$ Housing with 6 Occupants & 0.00 & 0.00 & 0.00 & 0.04 & 0.28 & 0.02 & 0.03 \\
\hline$\%$ Housing with $7+$ Occupants & 0.00 & 0.00 & 0.00 & 0.03 & 0.22 & 0.01 & 0.02 \\
\hline Median Rooms Owner-Occupied & 1.80 & 5.37 & 6.30 & 7.60 & 10.00 & 6.45 & 1.19 \\
\hline Median Rooms Renter-Occupied & 1.40 & 3.40 & 4.30 & 5.60 & 10.00 & 4.44 & 1.17 \\
\hline$\%$ Population Age 0-9 & 0.00 & 0.06 & 0.11 & 0.16 & 0.31 & 0.11 & 0.05 \\
\hline \% Population Age 10-17 & 0.00 & 0.04 & 0.08 & 0.14 & 0.30 & 0.09 & 0.05 \\
\hline$\%$ Population Age 18-29 & 0.00 & 0.08 & 0.15 & 0.24 & 0.88 & 0.16 & 0.09 \\
\hline \% Population Age 30-44 & 0.02 & 0.16 & 0.23 & 0.32 & 0.54 & 0.24 & 0.08 \\
\hline$\%$ Population Age 45-54 & 0.03 & 0.19 & 0.26 & 0.34 & 0.61 & 0.26 & 0.08 \\
\hline$\%$ Population Age $65+$ & 0.00 & 0.07 & 0.13 & 0.21 & 0.81 & 0.14 & 0.09 \\
\hline$\%$ Population White & 0.32 & 0.68 & 0.82 & 0.92 & 1.00 & 0.80 & 0.12 \\
\hline $\begin{array}{l}\text { \% Population Black/African } \\
\text { American }\end{array}$ & 0.00 & 0.00 & 0.01 & 0.08 & 0.39 & 0.04 & 0.06 \\
\hline \% Population Asian & 0.00 & 0.01 & 0.04 & 0.13 & 0.63 & 0.07 & 0.08 \\
\hline $\begin{array}{l}\text { \% Population White } \\
\text { Hispanic/Latino }\end{array}$ & 0.00 & 0.01 & 0.05 & 0.13 & 0.64 & 0.07 & 0.09 \\
\hline \% Population Hispanic/Latino & 0.00 & 0.02 & 0.08 & 0.20 & 0.75 & 0.11 & 0.12 \\
\hline \% Population Other Race & 0.00 & 0.00 & 0.01 & 0.06 & 0.50 & 0.03 & 0.06 \\
\hline \% Population Multi-Race & 0.00 & 0.01 & 0.04 & 0.09 & 0.28 & 0.05 & 0.04 \\
\hline $\begin{array}{l}\text { \% Population Limited English } \\
\text { Ability }\end{array}$ & 0.00 & 0.00 & 0.01 & 0.07 & 0.30 & 0.04 & 0.05 \\
\hline $\begin{array}{l}\text { \% Population Less than High } \\
\text { School Deg.* }\end{array}$ & 0.00 & 0.01 & 0.05 & 0.16 & 0.46 & 0.08 & 0.08 \\
\hline $\begin{array}{l}\text { \% Population High School } \\
\text { Deg./GED* }\end{array}$ & 0.00 & 0.07 & 0.17 & 0.28 & 0.62 & 0.17 & 0.10 \\
\hline $\begin{array}{l}\text { \% Population Associate's } \\
\text { Deg./Some College* }\end{array}$ & 0.03 & 0.19 & 0.30 & 0.40 & 0.59 & 0.30 & 0.10 \\
\hline \% Population Bachelor's Deg.* & 0.00 & 0.15 & 0.27 & 0.39 & 0.58 & 0.27 & 0.11 \\
\hline $\begin{array}{l}\text { \% Population } \\
\text { Graduate/Professional Deg.* }\end{array}$ & 0.00 & 0.05 & 0.15 & 0.30 & 0.65 & 0.17 & 0.12 \\
\hline$\%$ Population in Labor Force** & 0.20 & 0.59 & 0.69 & 0.79 & 0.96 & 0.69 & 0.10 \\
\hline$\%$ Population in Armed Forces** & 0.00 & 0.00 & 0.00 & 0.00 & 0.05 & 0.00 & 0.00 \\
\hline \% Population Full-time Worker** & 0.08 & 0.35 & 0.45 & 0.53 & 0.79 & 0.44 & 0.09 \\
\hline \% Population Part-time Worker** & 0.06 & 0.21 & 0.27 & 0.34 & 0.69 & 0.27 & 0.07 \\
\hline \% Population Did Not Work** & 0.04 & 0.19 & 0.28 & 0.37 & 0.77 & 0.28 & 0.10 \\
\hline
\end{tabular}

*Aged 25 years or older; **Aged 16 years or older 